\title{
Potential glycemic overtreatment in patients $\geq 75$ years with type 2 diabetes mellitus and renal disease: experience from the observational OREDIA study
}

This article was published in the following Dove Press journal: Diabetes, Metabolic Syndrome and Obesity:Targets and Therapy 3 July 2015

Number of times this article has been viewed

\author{
Alfred Penfornis' \\ Béatrice Fiquet ${ }^{2}$ \\ Jean Frédéric Blicklé ${ }^{3}$ \\ Sylvie Dejager ${ }^{2,4}$
}

'Department of Endocrinology and Diabetology, Centre Hospitalier Sud Francilien, Corbeil-Essonnes Cedex, France; ${ }^{2}$ Clinical Affairs, Novartis Pharma SAS, Rueil-Malmaison, France; ${ }^{3}$ Department of Internal Medicine and Diabetology, Strasbourg University Hospital, Strasbourg, France; ${ }^{4}$ Department of Diabetology, Metabolism and Endocrinology, PitiéSalpétrière Hospital, Paris, France
Correspondence: Sylvie Dejager Clinical Affairs, Novartis Pharma SAS, 10 rue Lionel Terray, 92506 RueilMalmaison, France

Tel +33 | 55476339

Fax +33 I 55476593

Email sylvie.dejager@psl.aphp.fr
Background: Few data exist examining the management of elderly patients with type 2 diabetes mellitus and renal impairment (RI). This observational study assessed the therapeutic management of this fragile population.

Methods: Cross-sectional study: data from 980 diabetic patients $\geq 75$ years with renal disease are presented.

Results: Patients had a mean age of 81 years (range 75-101) with long-standing diabetes (15.4 years) often complicated (half with macrovascular disease). Mean estimated glomerular filtration rate was $43 \mathrm{~mL} / \mathrm{min} / 1.73 \mathrm{~m}^{2}$ and $20 \%$ had severe RI. Mean hemoglobin $\mathrm{A}_{1 \mathrm{c}}$ was $7.4 \%$. Anti-diabetic therapy was oral based for $51 \%$ of patients $(60 \% \geq 2$ oral anti-diabetic drugs [OAD]) and insulin based for $49 \%$ (combined with OAD in 59\%). OAD included metformin (47\%), sulfonylureas (26\%), glinides (19\%), and DPP-4 inhibitors (31\%). Treatments were adjusted to increasing RI, with less use of metformin, sulfonylureas, and DPP-4 inhibitors, and more glinides and insulin in severe RI. In all, 579 (60\%) of these elderly patients with comorbidities had hemoglobin $A_{1 c}<7.5 \%$ (mean 6.7\%) while being intensively treated: $69 \%$ under insulin-secretagogues and/or insulin, putting them at high risk for severe hypoglycemia. Only one-fourth were under oral monotherapy.

Conclusion: In clinical practice, a substantial proportion of elderly patients may be overtreated. RI is insufficiently taken into account when prescribing OAD.

Keywords: elderly, hypoglycemia, overtreatment, renal impairment, sulfonylureas, type 2 diabetes mellitus

\section{Introduction}

Type 2 diabetes mellitus (T2DM) is an important health issue in the elderly with a prevalence of approximately $20 \%$ in individuals $\geq 75$ years in France. ${ }^{1}$ Worldwide, the highest age-specific prevalence is in the adult group aged 60-79 years (18.6\%) according to the latest estimates of the International Diabetes Federation Diabetes Atlas. ${ }^{2}$ With the overall aging of the population and the increasing prevalence of diabetes with age seen across all regions and income groups, the number of elderly patients with T2DM is thus continuously growing worldwide.

Elderly diabetic patients constitute a markedly heterogeneous population, in whom individualization of treatment is especially important. ${ }^{3-5}$ Diabetes in elderly people is also associated with an increased risk of renal impairment (RI), because of the high prevalence of T2DM-related complications, higher prevalence of cardiovascular $(\mathrm{CV})$ 
disease and hypertension, and because of the age-related decline in renal function (RF). ${ }^{6-9}$ Management of T2DM in case of RI is more complex and treatment options are more limited in particular because of the higher risk and more severe consequences of hypoglycemia. ${ }^{3}$ Other challenges include the presence of numerous comorbidities, a high prevalence of polypharmacy, posing an increased risk for drugdrug interaction, and differential clearance and/or metabolism of anti-hyperglycemic agents, with the need for dose adjustment and regular monitoring of RF. ${ }^{6,10,11}$ In most guidelines, reasonable hemoglobin $\mathrm{A}_{1 \mathrm{c}}\left(\mathrm{HbA}_{1 \mathrm{c}}\right)$ targets for non-dependent elderly diabetic patients would be between $7.5 \%$ and $8 \%$ depending on the level of comorbidities. ${ }^{3}$

Despite the high prevalence and significant burden of the disease in the elderly population, few data are available from randomized clinical trials or from real-life experience in elderly patients with diabetes and comorbidities. On one hand, this dearth of evidence could lead to under-treatment in this population, ${ }^{11}$ but on the other hand the possibility of overtreatment of these vulnerable individuals at high risk of adverse hypoglycemic events also has to be considered. ${ }^{12}$

It was therefore of particular interest to investigate how physicians manage this fragile population of patients $\geq 75$ years with T2DM and renal disease in real life at routine clinical visits. This was assessed in the OREDIA (Observation of patients with REnal disease and DIAbetes) cross-sectional study conducted in France in 2012 to look at the therapeutic management of T2DM patients with chronic kidney disease (CKD) and to evaluate how RF was taken into account for treatment decisions. ${ }^{13}$

\section{Patients and methods}

This was a sub-analysis of data in patients $\geq 75$ years old from the previously published OREDIA study. ${ }^{13}$ OREDIA was a multicenter, observational, cross-sectional study conducted in France between June 1, 2012 and January 28, 2013, in which 968 physicians (general practitioners [GPs] and diabetologists [DBs]) recruited about 3,700 patients. Details of the study design are described elsewhere. ${ }^{13}$ Briefly, each participating physician was asked to include the first two consecutive patients with T2DM who they considered to have CKD and the first patient who they considered not to. All patients included in the study had been diagnosed with T2DM at least 1 year previously and were treated with oral anti-diabetic drugs (OAD) agents \pm insulin or insulin alone, in addition to lifestyle management. All were outpatients, thus probably without significant mobility or cognitive impairments, but frailty was not formally assessed.
Patients were then further classified by their estimated glomerular filtration rate (eGFR) (Modification of Diet in Renal Disease formula) as having normal RF (eGFR $\geq 60 \mathrm{~mL} / \mathrm{min} / 1.73 \mathrm{~m}^{2}$ ), moderate RI (eGFR $30-60 \mathrm{~mL} /$ $\left.\mathrm{min} / 1.73 \mathrm{~m}^{2}\right)$, or severe RI (eGFR $\left.<30 \mathrm{~mL} / \mathrm{min} / 1.73 \mathrm{~m}^{2}\right)$.

Sociodemographic, clinical, and biological data were collected during the single study visit and included: age, sex, disease history, comorbidities, diabetes complications, CV risk factors and concomitant therapies, available biological data including $\mathrm{HbA}_{1 \mathrm{c}}$ and urinary albumin excretion rate (UAER) (no test was required by the protocol in this observational study), and current anti-diabetic treatments (by therapeutic classes). In addition, physicians were asked whether they had changed the anti-diabetic treatment at the end of the study visit.

\section{Assessments}

The current paper aims to describe the therapeutic management (anti-diabetic treatments and drugs for CV risk management by therapeutic class) in the subpopulation of patients $\geq 75$ years with T2DM and considered to have CKD according to physicians' judgment. Furthermore, we specifically looked at patients with $\mathrm{HbA}_{1 \mathrm{c}}$ levels $<7.5 \%$ whose glycemic control could be considered as intensive in view of their age, the presence of CKD, and the prevalence of associated comorbidities. ${ }^{3,5}$ A patient was considered to be potentially overtreated when he/she was receiving multiple oral therapies, besides metformin, including oral insulin-secretagogues (IS: sulfonylureas [SU] and glinides) or insulin. Finally, we also described management of T2DM according to the physician who included the patient (GP or DB).

\section{Statistical analyses}

Quantitative or continuous variables were described by mean and standard deviation (SD) and, in some cases, median and range. Qualitative variables were described by absolute frequency and percentage per modality. Quantitative variables were compared between groups by Student's $t$-tests. Qualitative variables were compared between groups using the Pearson Chi-square test if all theoretical sample sizes were $>5$ or using the Fisher's test if $<5$. All tests were adjusted with a significance level of 5\%. All the analyses were performed on the overall population of patients analyzed (patients $\geq 75$ years with CKD) and in those included by GPs and by DBs. Other specific analyses were conducted in elderly patients with $\mathrm{CKD}$ and $\mathrm{HbA}_{1 \mathrm{c}}<7.5 \%$. Missing data were not replaced. Analyzed population was defined as all patients who fulfilled all inclusion criteria with no major protocol deviations. 
All statistical analyses were performed using SAS 8.2 software (SAS Institute, Cary, NC, USA).

\section{Ethics}

This observational study was conducted in accordance with the rules of the French Order of Physicians and Good Practices for Epidemiological Studies. Candidates for inclusion were provided with full information about the study in writing. All data processing was carried out in compliance with French Information Technology and Privacy Law.

\section{Results}

\section{Demographic and disease characteristics of the elderly population with CKD}

A total of 3,704 patients were analyzed in the main study..$^{13}$ Of these, 1,168 patients were $\geq 75$ years and 980 were considered to have $\mathrm{CKD}$, constituting our population for this sub-analysis: 771 were included by GPs and 209 by DBs (Figure 1).

The mean age of the population of interest was 81 years (range 75-101), 56\% were male, the mean body mass index was $29 \mathrm{~kg} / \mathrm{m}^{2}$ and most patients had a long diabetes history (mean duration of 15 years with $51 \%$ having $\geq 15$ years of disease duration). Nearly all the patients had at least one associated CV risk factor, mainly hypertension (96\%) and dyslipidemia (78\%). Consequently, most patients were on multiple concomitant therapies, primarily represented by antihypertensive (95.5\%), lipid-lowering (74.5\%), and anti-platelet agents $(64.8 \%)$. The mean number of co-medications was $5.5 \pm 2.8$. Diabetic complications were highly prevalent $(89 \%)$ driven by nephropathy (75\%), macrovascular complications (49\%), symptomatic heart failure (21\%), and retinopathy (20\%). Mean eGFR was $43 \mathrm{~mL} / \mathrm{min} / 1.73 \mathrm{~m}^{2}: 20 \%$ of the patients had severe RI (eGFR $<30 \mathrm{~mL} / \mathrm{min} / 1.73 \mathrm{~m}^{2}$; mean of $22.5 \mathrm{~mL} / \mathrm{min} / 1.73 \mathrm{~m}^{2}$ ), $71 \%$ had moderate RI (eGFR between 60 and $30 \mathrm{~mL} / \mathrm{min} / 1.73 \mathrm{~m}^{2}$, mean of $43.7 \mathrm{~mL} / \mathrm{min} / 1.73 \mathrm{~m}^{2}$ ), and $9 \%$ had normal RF. Most (87\%) of the patients with normal RF had abnormal UAER and had thus been appropriately classified with CKD by the physicians. The mean $\mathrm{HbA}_{1 \mathrm{c}}$ was 7.4\%: $59 \%$ of the patients had an $\mathrm{HbA}_{1 \mathrm{c}}$ of $<7.5 \%$ and $24 \%$ had an $\mathrm{HbA}_{1 \mathrm{c}}$ of $\geq 8 \%$. The demographic characteristics are presented in more detail in Table 1 along with the type of physician (GP or DB). Compared with those included by the GPs, patients included by the DBs had a longer diabetes history $(P<0.001)$ despite a similar mean age, a higher prevalence of complications but the same mean eGFR (Table 1). Their glycemic control was less strict $(P<0.001)$ and $42 \%$ (vs $64 \%$ for patients included by GPs) had an $\mathrm{HbA}_{1 \mathrm{c}}$ of $<7.5 \%(P<0.001)$. Overall, $81.5 \%$ of the patients were also followed by a cardiologist and $38.2 \%$ by a nephrologist.

\section{Therapeutic management of T2DM in the elderly population with CKD}

Overall, anti-diabetic therapy was based on oral agents alone in $51 \%$ of the patients ( $40 \%$ as a single agent, $46 \%$ as dual therapy, and $13 \%$ as triple or more) and on insulin in $49 \%$ (alone in $41 \%$ and combined with one or more OAD in 59\%).

Metformin was prescribed in $47 \%$ of the patients. The mean daily dose of metformin was $2,000 \mathrm{mg} ; 25 \%$ were

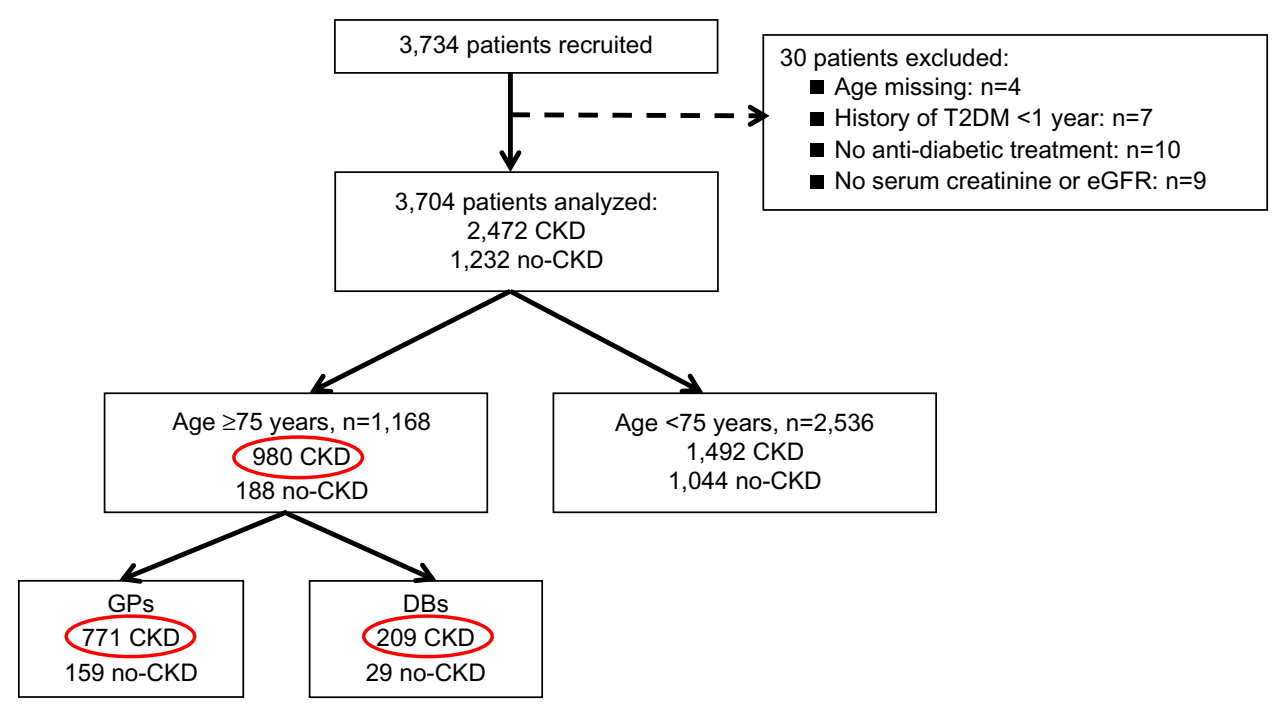

Figure I Flow chart of patients' disposition.

Note: The red circles show the subgroup of patients from the OREDIA main study.

Abbreviations: CKD, chronic kidney disease; DBs, diabetologists; eGFR, estimated glomerular filtration rate; GPs, general practitioners; T2DM, type 2 diabetes mellitus. 
Table I Demographic and disease characteristics according to physicians: whole population

\begin{tabular}{|c|c|c|c|c|}
\hline & $\begin{array}{l}\text { GPs } \\
N=77 \text { I }\end{array}$ & $\begin{array}{l}\text { DBs } \\
N=209\end{array}$ & $\begin{array}{l}P \text {-value } \\
\text { GP vs DB }\end{array}$ & $\begin{array}{l}\text { Total } \\
\mathrm{N}=980\end{array}$ \\
\hline Age (years, mean $\pm S D$ ) & $80.7 \pm 4.4$ & $80.7 \pm 3.9$ & 0.849 & $80.7 \pm 4.3$ \\
\hline Sex (\% male) & 55.8 & 55.0 & $0.832^{*}$ & 55.7 \\
\hline BMI $\left(\mathrm{kg} / \mathrm{m}^{2}\right.$, mean $\left.\pm \mathrm{SD}\right)$ & $28.6 \pm 4.8$ & $29.2 \pm 4.7$ & 0.128 & $28.7 \pm 4.8$ \\
\hline Duration of T2DM (years, mean \pm SD) & $14.2 \pm 7.9$ & $19.7 \pm 10.6$ & $<0.001$ & $15.4 \pm 8.8$ \\
\hline$\%$ of patients with $\geq 15$ years duration & 46.4 & 66.0 & $<0.00 I^{*}$ & 50.6 \\
\hline $\mathrm{HbA}_{\mathrm{Ic}}(\%$, mean $\pm \mathrm{SD})$ & $7.3 \pm 1.0$ & $7.8 \pm 1.2$ & $<0.001$ & $7.4 \pm 1.1$ \\
\hline$<7 \%, \%$ of patients & 40.1 & 21.5 & $<0.00 I^{*}$ & 36.1 \\
\hline $7 \%-7.5 \%, \%$ of patients & 24.1 & 20.6 & & 23.3 \\
\hline $7.5 \%-8 \%, \%$ of patients & 14.9 & 23.4 & & 16.7 \\
\hline$\geq 8 \%$, $\%$ of patients & 20.9 & 34.4 & & 23.8 \\
\hline At least one complication, $\%$ of patients & 87.5 & 93.8 & $0.024 * *$ & 88.9 \\
\hline Microvascular & 78.3 & 90.0 & $<0.00 I^{*}$ & 80.8 \\
\hline Retinopathy & 19.2 & 23.0 & $0.227^{*}$ & 20.0 \\
\hline Nephropathy & 71.5 & 85.6 & $<0.00 I^{*}$ & 74.5 \\
\hline Neuropathy & 15.0 & 31.1 & $<0.00 I^{*}$ & 18.5 \\
\hline Macrovascular & 46.7 & 56.5 & $0.012^{*}$ & 48.8 \\
\hline Coronary heart disease & 28.1 & 39.2 & $0.002^{*}$ & 30.5 \\
\hline Cerebrovascular disease & 10.6 & 11.0 & $0.878^{*}$ & 10.7 \\
\hline Lower limb arteriopathy & 19.7 & 22.5 & $0.377^{*}$ & 20.3 \\
\hline Symptomatic heart failure & 23.2 & 10.5 & $<0.001 *$ & 20.5 \\
\hline At least one $C V$ risk factor, $\%$ of patients & 99.3 & 99.5 & $1.000^{* *}$ & 99.4 \\
\hline Hypertension & 95.5 & 97.1 & $0.285^{*}$ & 95.8 \\
\hline Dyslipidemia & 75.2 & 86.6 & $0.00 I^{*}$ & 77.7 \\
\hline Sedentary lifestyle & 53.4 & 47.8 & $0.15 I^{*}$ & 52.2 \\
\hline \multicolumn{5}{|l|}{ Management of $\mathrm{CV}$ risk } \\
\hline Number of co-medications ${ }^{\mathrm{a}}$, mean $\pm \mathrm{SD}$ & $5.4 \pm 2.8$ & $6.1 \pm 2.8$ & 0.007 & $5.5 \pm 2.8$ \\
\hline Lipid-lowering drugs, \% of patients & 71.7 & 84.7 & $<0.00 I^{*}$ & 74.5 \\
\hline Anti-platelet therapies, $\%$ of patients & 64.3 & 66.5 & $0.559 *$ & 64.8 \\
\hline Anti-hypertensive treatments, $\%$ of patients & 95.1 & 97.1 & $0.203^{*}$ & 95.5 \\
\hline$\geq 3$ Anti-hypertensive drugs, $\%$ of patients & 40.1 & 51.7 & $0.003^{*}$ & 42.6 \\
\hline One/two RAAS blockers, \% of patients & $73.3 / 2.9$ & $77.5 / 4.3$ & $0.147^{*}$ & $74.2 / 3.2$ \\
\hline eGFR $\left(\mathrm{mL} / \mathrm{min} / \mathrm{I} .73 \mathrm{~m}^{2}\right.$, mean $\left.\pm \mathrm{SD}\right)$ & $43.1 \pm 17.4$ & $4 I .3 \pm 14.0$ & 0.117 & $42.7 \pm 16.8$ \\
\hline$<30, \%$ of patients & 20.1 & 17.7 & $0.378^{*}$ & 19.6 \\
\hline $30-60, \%$ of patients & 69.9 & 74.6 & & 70.9 \\
\hline$\geq 60, \%$ of patients & 10.0 & 7.7 & & 9.5 \\
\hline \multicolumn{5}{|l|}{ UAER, \% of patients ${ }^{\mathrm{b}}$} \\
\hline Microalbuminuria & 51.9 & 40.6 & $0.020^{*}$ & 49.2 \\
\hline Macroalbuminuria & 27.8 & 29.7 & & 28.3 \\
\hline \multicolumn{5}{|l|}{ Specialists' involvement, \% of patients } \\
\hline Diabetologist & 42.3 & 100 & $<0.00 I^{*}$ & 54.6 \\
\hline Nephrologist & 36.6 & 44.0 & $0.049 *$ & 38.2 \\
\hline Cardiologist & 80.9 & 83.7 & $0.355^{*}$ & 81.5 \\
\hline
\end{tabular}

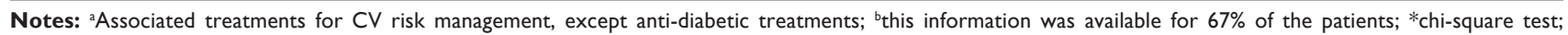
**Fisher's test. $\mathrm{N}=$ the number of patients.

Abbreviations: BMI, body mass index; CV, cardiovascular; DB, diabetologist; eGFR, estimated glomerular filtration rate; GPs, general practitioners; HbA ${ }_{I c}$, hemoglobin $A_{1 c}$; RAAS, renin angiotensin aldosterone system; SD, standard deviation; T2DM, type 2 diabetes mellitus; UAER, urinary albumin excretion rate.

receiving $>2,000 \mathrm{mg} /$ day and $15 \%$ a dose of $\geq 3,000 \mathrm{mg} /$ day. SU, glinides, and DPP-4 inhibitors accounted for respectively $26 \%, 19 \%$, and $31 \%$ of the prescriptions while the prescription of alpha-glucosidase inhibitors was marginal $(6 \%)$.

When the prescriptions were further analyzed according to the actual eGFR of the patients, the use of metformin, SU, and DPP-4 inhibitors significantly decreased with increasing severity of RI while that of glinides and insulin increased. Metformin was used by $70 \%$ of patients with normal RF, $49 \%$ and $29 \%$ of those with moderate and severe RI, respectively $(P<0.001)$. The SU use decreased with RF $(28 \%, 28 \%$, and $19 \%$ in normal RF, moderate and severe RI, respectively; $P=0.001)$ as did the use of DPP-4 inhibitors $(38 \%, 33 \%$, and $20 \%$, respectively; $P<0.001$ ), while that of glinides 
(11\%, 19\%, and $21 \%$, respectively; $P=0.012)$ and of insulin increased $(37 \%, 46 \%$, and $65 \%$, respectively; $P<0.001)$. The use of anti-diabetic drugs according to RF is presented by specialty (GPs and DBs) in Figure 2. Overall, the use of insulin was higher in patients included by DBs $(75 \%$ vs $42 \%$ in patients included by GPs; $P<0.001$ ), and did not change meaningfully according to RF. Conversely, the use of metformin was higher in patients included by GPs $(53 \%$ vs $26 \%$ in patients included by DBs; $P<0.001$ ), as was the use of SU ( $28 \%$ by GPs vs $20 \%$ by DBs; $P=0.02$ ). For other anti-diabetic drugs, trends for adjustments by degree of RI followed the same pattern for DBs and GPs even if adjustments were more pronounced in patients included by DBs (Figure 2). In the subpopulation with severe RI, a smaller proportion of patients included by DBs tended to receive metformin ( $22 \%$ vs $31 \%$ of patients included by GPs) and
SU ( $8 \%$ vs $21 \%$ ), while more were under glinides (30\% vs 19\%) (all comparisons were non-significant).

Overall, treatment was modified at the end of the visit in about $27 \%$ of the patients. In the sub-group of patients with severe RI, metformin was reduced/stopped in $40 \%$ of the patients, and significantly less often for patients included by GPs (about 30\%) than for those included by DBs (100\%) $(P<0.001)$. In this same group of patients with severe RI, SU were stopped in only $9 \%$ of the patients included by GPs but also in $100 \%$ of those included by DBs $(P<0.01)$.

\section{Management of the sub-group of patients with intensive glycemic control $\left(\mathrm{HbA}_{\mathrm{Ic}}<7.5 \%\right)$}

More than half of the patients $(n=579,59.1 \%)$ had a strict glycemic control with a mean $\mathrm{HbA}_{1 \mathrm{c}}$ of $6.7 \% \pm 0.5 \%$; among
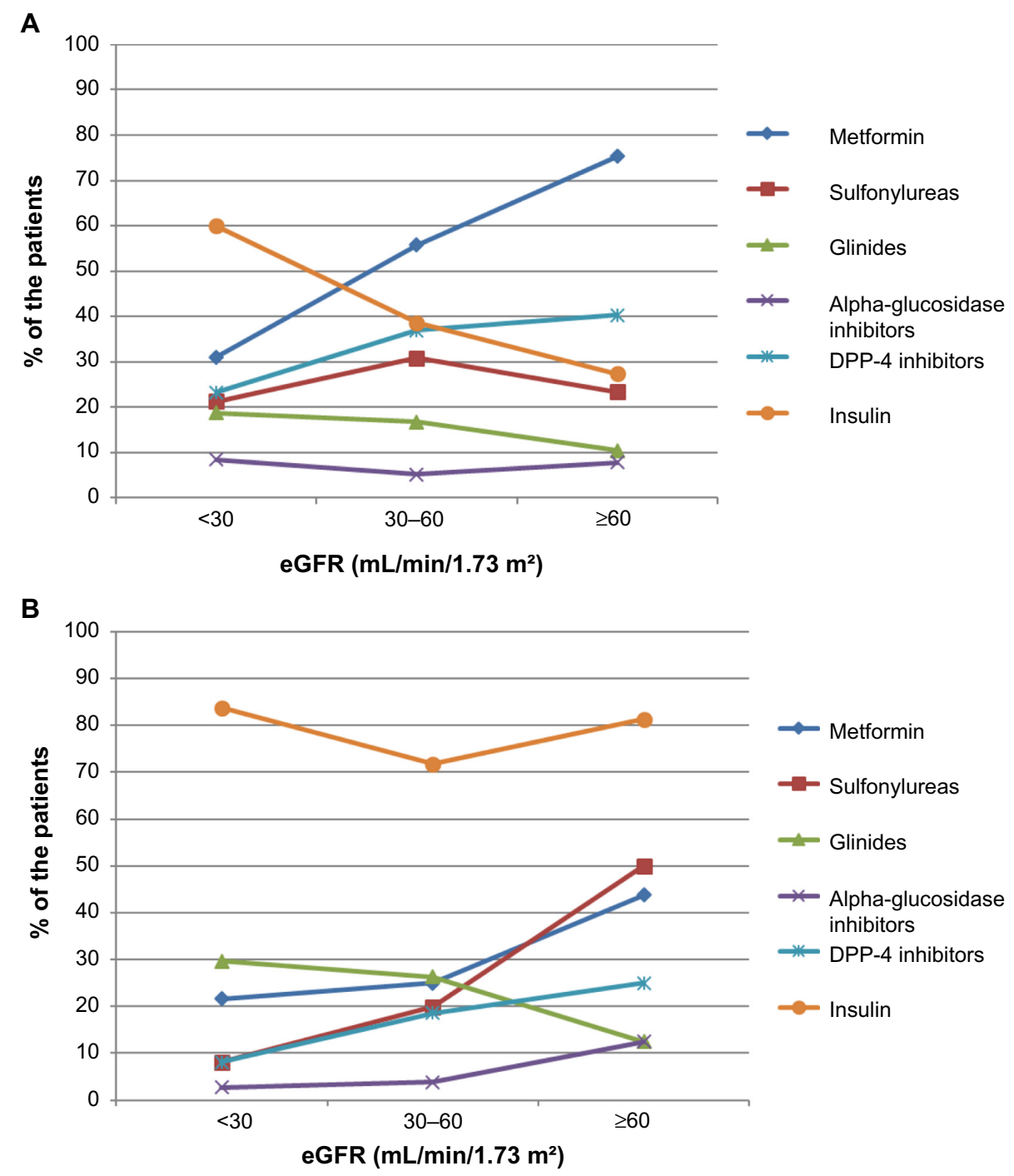

Figure 2 Therapeutic management of T2DM by eGFR status and by physicians.

Note: (A) GPs and (B) diabetologists.

Abbreviations: eGFR, estimated glomerular filtration rate; GPs, general practitioners; T2DM, type 2 diabetes mellitus. 
them $60.8 \%$ had an $\mathrm{HbA}_{1 \mathrm{c}}$ of $<7 \%$. The demographic characteristics, multiple associated $\mathrm{CV}$ risk factors, and diabetes complications were similar to those of the whole population of elderly patients (Table 2): mean age 81 years, mean diabetes duration of 15 years, $47 \%$ of these patients had at least one macrovascular complication; their mean eGFR was $43 \mathrm{~mL} / \mathrm{min} / 1.73 \mathrm{~m}^{2}$ and $18.7 \%$ had severe RI. In addition, polypharmacy was common in this population (with a mean of 5.6 \pm 3.1 co-medications, besides anti-diabetic treatment).
Only one quarter of these patients received a single OAD, and most were on either dual or triple OAD therapy or insulin (Figure 3). Two-thirds (69\%) of these patients received oral insulin secretagogues (SU or glinides, 28.3\%) and exogenous insulin (40.3\%).

\section{Discussion}

This work suggests that, in routine clinical practice, a substantial number of elderly T2DM patients with

Table 2 Demographic and disease characteristics according to physicians: patients with $\mathrm{HbA}_{\mathrm{lc}}<7.5 \%$

\begin{tabular}{|c|c|c|c|c|}
\hline & $\begin{array}{l}\text { GPs } \\
N=491\end{array}$ & $\begin{array}{l}\text { DBs } \\
N=88\end{array}$ & $\begin{array}{l}P \text {-value } \\
\text { GP vs DB }\end{array}$ & $\begin{array}{l}\text { Total } \\
\mathbf{N}=\mathbf{5 7 9}\end{array}$ \\
\hline Age (years, mean $\pm S D$ ) & $80.6 \pm 4.4$ & $80.5 \pm 4.3$ & 0.901 & $80.6 \pm 4.4$ \\
\hline Sex (\% male) & 59.4 & 62.5 & $0.583^{*}$ & 59.9 \\
\hline $\mathrm{BMI}\left(\mathrm{kg} / \mathrm{m}^{2}\right.$, mean $\left.\pm \mathrm{SD}\right)$ & $28.4 \pm 4.7$ & $29.4 \pm 4.4$ & 0.73 & $28.5 \pm 4.6$ \\
\hline Duration of T2DM (years, mean $\pm \mathrm{SD}$ ) & $13.4 \pm 7.9$ & $20.5 \pm 10.6$ & $<0.001$ & $14.5 \pm 8.7$ \\
\hline $\mathrm{HbA}_{\mathrm{Ic}}(\%$, mean $\pm \mathrm{SD})$ & $6.7 \pm 0.5$ & $6.8 \pm 0.4$ & $0.04 I$ & $6.7 \pm 0.5$ \\
\hline$<7 \%$, \% of patients & 62.5 & 51.1 & $0.044^{*}$ & 60.8 \\
\hline$\geq 7$ and $<7.5 \%, \%$ of patients & 37.5 & 48.9 & & 39.2 \\
\hline At least one complication, $\%$ of patients & 85.5 & 95.5 & $0.028 * *$ & 87.0 \\
\hline Microvascular & 74.7 & 89.8 & $0.002^{*}$ & 77.0 \\
\hline Retinopathy & 17.3 & 25.0 & $0.087^{*}$ & 18.5 \\
\hline Nephropathy & 68.2 & 84.1 & $0.003^{*}$ & 70.6 \\
\hline Neuropathy & 14.5 & 35.2 & $<0.001$ & 17.6 \\
\hline Macrovascular & 44.6 & 62.5 & $0.002 *$ & 47.3 \\
\hline Coronary heart disease & 27.5 & 43.2 & $0.003^{*}$ & 29.9 \\
\hline Cerebrovascular disease & 9.2 & 12.5 & $0.330 *$ & 9.7 \\
\hline Lower limb arteriopathy & 18.9 & 25.0 & $0.190 *$ & 19.9 \\
\hline Symptomatic heart failure & 22.6 & 13.6 & $0.058 *$ & 21.2 \\
\hline At least one CV risk factor, $\%$ of patients & 99.2 & 100 & $1.000 * *$ & 99.3 \\
\hline Hypertension & 96.3 & 97.7 & $0.753 * *$ & 96.5 \\
\hline Dyslipidemia & 73.7 & 88.6 & $0.003^{*}$ & 76.0 \\
\hline Sedentary lifestyle & 52.7 & 51.1 & $0.780 *$ & 52.5 \\
\hline \multicolumn{5}{|l|}{ Management of $\mathrm{CV}$ risk } \\
\hline Number of co-medications $s^{\mathrm{a}}$, mean $\pm \mathrm{SD}$ & $5.4 \pm 3.0$ & $6.9 \pm 3.2$ & $<0.001$ & $5.6 \pm 3.1$ \\
\hline Lipid-lowering drugs, $\%$ of patients & 69.7 & 87.5 & 0.001 & 72.4 \\
\hline Anti-platelet therapies, $\%$ of patients & 62.1 & 71.6 & 0.089 & 63.6 \\
\hline Anti-hypertensive treatments, $\%$ of patients & 95.9 & 97.7 & $0.555^{* *}$ & 96.2 \\
\hline$\geq 3$ Anti-hypertensive drugs, $\%$ of patients & 38.5 & 51.1 & $0.026^{*}$ & 40.4 \\
\hline One/two RAAS blockers, \% of patients & $72.7 / 3.3$ & $76.1 / 3.4$ & $0.767^{*}$ & $73.2 / 3.3$ \\
\hline eGFR $\left(\mathrm{mL} / \mathrm{min} / \mathrm{I} .73 \mathrm{~m}^{2}\right.$, mean $\left.\pm \mathrm{SD}\right)$ & $43.5 \pm 17.6$ & $40.7 \pm 16.3$ & 0.170 & $43.1 \pm 17.5$ \\
\hline$<30, \%$ of patients & 18.3 & 20.5 & $0.558^{*}$ & 18.7 \\
\hline $30-60, \%$ of patients & 71.3 & 72.7 & & 71.5 \\
\hline$\geq 60, \%$ of patients & 10.4 & 6.8 & & 9.8 \\
\hline \multicolumn{5}{|l|}{ UAER, $\%$ of patients ${ }^{b}$} \\
\hline Microalbuminuria & 49.5 & 39.1 & $0.070 *$ & 47.7 \\
\hline Macroalbuminuria & 27.4 & 24.6 & & 26.9 \\
\hline \multicolumn{5}{|l|}{ Specialists' involvement, \% of patients } \\
\hline Diabetologist & 39.3 & 100 & $<0.00 I^{*}$ & 48.5 \\
\hline Nephrologist & 37.1 & 47.7 & $0.059 *$ & 38.7 \\
\hline Cardiologist & 80.2 & 86.4 & $0.176 *$ & 81.2 \\
\hline
\end{tabular}

Notes: ${ }^{a}$ Associated treatments for CV risk management, except anti-diabetic treatments; ${ }^{b}$ this information was available for $67 \%$ of the patients; ${ }^{*}$ chi-square test; $* *$ Fisher's test. $\mathrm{N}=$ the number of patients.

Abbreviations: $\mathrm{BMI}$, body mass index; $\mathrm{CV}$, cardiovascular; $\mathrm{DB}$, diabetologist; eGFR, estimated glomerular filtration rate; GPs, general practitioners; $\mathrm{Hb} \mathrm{A}_{\mathrm{Ic}}$, hemoglobin $\mathrm{A}_{\mathrm{Ic}}$; RAAS, renin angiotensin aldosterone system; SD, standard deviation; T2DM, type 2 diabetes mellitus; UAER, urinary albumin excretion rate. 


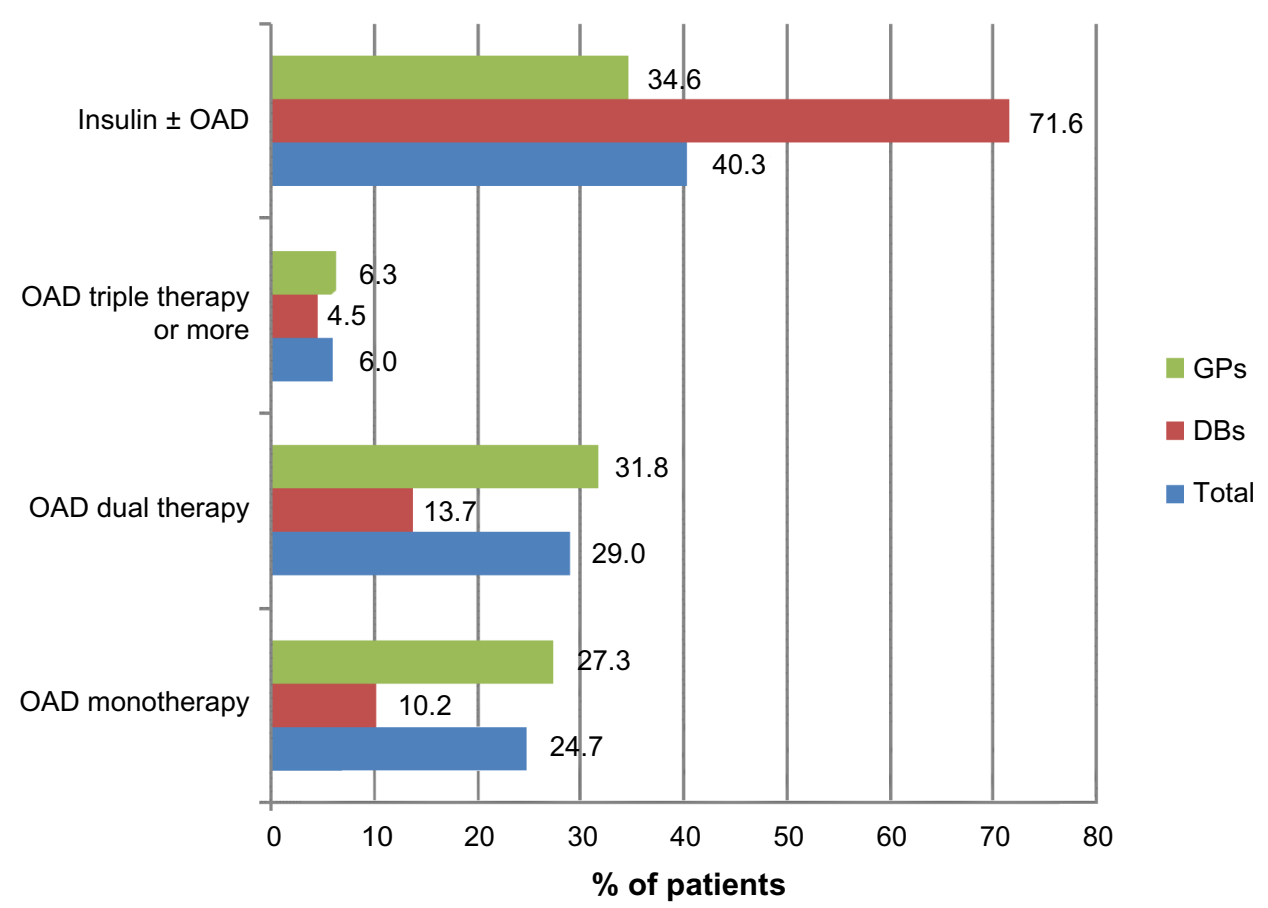

Figure 3 Anti-diabetic treatment in patients with $\mathrm{HbA}_{\mathrm{Ic}}<7.5 \%$ (mean 6.7\%).

Abbreviations: DBs, diabetologists; GPs, general practitioners; $\mathrm{HbA}_{\mathrm{lc}}$, hemoglobin $\mathrm{A}_{\mathrm{lc}}$; $\mathrm{OAD}$, oral anti-diabetic drugs.

CKD and overt RI may be overtreated. In our study, $60 \%$ of these elderly patients with advanced disease had an $\mathrm{HbA}_{1 \mathrm{c}}$ of $<7.5 \%$ but were still being quite intensively treated. Most were receiving multiple oral drug therapies and/or insulin. Moreover, $69 \%$ of them were receiving anti-diabetic treatments that increase insulin levels independently of the blood glucose level, such as oral IS and/ or insulin, putting them at considerable risk of severe hypoglycemia. In addition, RI was insufficiently taken into account by GPs when adjusting anti-diabetes medications, especially SU.

Glycemic overtreatment has emerged as a concern in this population worldwide. The need to balance benefit and harm for each individual, and thus to tailor the goals and individualize therapeutic options, has been clearly recognized and re-emphasized by all recent guidelines for the management of diabetes in elderly individuals ${ }^{3,5,14}$ and in patients with renal disease. ${ }^{15}$

However, even if generally advocated by all, this principle of treatment individualization may be far from being systematically applied in clinical practice. In this regard, our data suggesting potential diabetic overtreatment is not surprising. While this issue was previously largely unrecognized, several recent studies across the world have reported the reality and magnitude of the problem and its potential harmful consequences. ${ }^{12}$
In the US, the extent of potential diabetic overtreatment was evaluated within 139 Veterans Health Administration facilities by looking at patients receiving insulin and/or SU who had evidence of intensive glycemic management and thus who were at risk of serious hypoglycemia. ${ }^{16}$ Approximately half of the elderly patients (aged $\geq 75$ years; mean of 80.6 years), who also had either a serum creatinine of $>2.0 \mathrm{mg} / \mathrm{dL}$ or a diagnosis of cognitive impairment, had evidence of intensive treatment with an $\mathrm{HbA}_{1 \mathrm{c}}$ of $<7 \%$. For many patients, less intensive goals and evaluation of other options for glycemic management would have been appropriate. ${ }^{16}$ Additional data in the US ${ }^{17}$ from the National Health and Nutrition Examination Survey also showed overtreatment in a subset of 756 T2DM patients aged $>65$ years (mean 73 years) with long-standing disease $(66.4 \%$ with diabetes history $>10$ years) and a high prevalence of $\mathrm{CV}$ disease (46.7\%). Their mean $\mathrm{HbA}_{\mathrm{lc}}$ was $6.8 \%$ and $\sim 81 \%$ were pharmacology treated, $60 \%$ with anti-diabetic medications besides metformin, and $40 \%$ with SU. ${ }^{17}$ Further, in the Diabetes and Aging Study (DAS), ${ }^{18}$ a retrospective cohort study of Kaiser Permanente Northern California, the mean $\mathrm{HbA}_{1 \mathrm{c}}$ in a cohort aged $\geq 60$ years (mean $71 \pm 7.4$ years) with mean disease duration of 8.3 years, was $7 \%$. While $15 \%$ of the patients had an $\mathrm{HbA}_{1 \mathrm{c}}$ level of $<6 \%$ and $60 \%$ a level $<7 \%$, SU were still the most frequently prescribed treatment (in 51\% of patients), followed by metformin in $38 \%$ and insulin in 
$18 \%{ }^{18}$ Although none of these studies correlated the rate of overtreatment with the risk of hypoglycemia, recent data show that severe hypoglycemia represents an important cause of hospitalization among elderly people in the $\mathrm{US}^{19}$ and that rates of hospital admissions for hypoglycemia now exceed those for hyperglycemia in US-Medicare beneficiaries. ${ }^{20}$

In France, potential overtreatment has also been reported among elderly, institutionalized patients of mean age 82 years, who had a mean $\mathrm{HbA}_{1 \mathrm{c}}$ of $7.19 \%$. At least one third of this population in long-term care homes was strictly controlled with an $\mathrm{HbA}_{1 \mathrm{c}}$ of $<6.5 \%$ with $66 \%$ of them being treated, including SU or insulin. ${ }^{21}$ Another more recent study ${ }^{22}$ described drug treatment for diabetes in 6,275 nursing home residents in France (mean age 86 years) of whom 1,076 (17.1\%) had diabetes. Among the diabetic patients, 722 (67\%) were receiving IS (insulin and/or SU) treatment, and patients in this IS group had a higher probability of emergency department visits in the last year and of disability. ${ }^{22}$

Overall, as recently outlined by Andrews and O'Malley, ${ }^{23}$ physicians need to understand the scope of potential diabetic overtreatment in everyday practice and seek to improve it.

This reluctance to scale down therapy when indicated may be the other side of the coin of clinical inertia. ${ }^{23}$ Several hypotheses could be evoked to explain overtreatment. First, physicians may fail to recognize the changing and declining health status of their patients while seeing them at routine appointments to refill prescriptions. Second, physicians could feel overwhelmed with guidelines and new developments, with sometimes conflicting information, such as in the case of metformin use in CKD patients. Finally, there may be a reluctance to discuss reducing medication when this could be perceived by the patient as a consequence of declining health.

However, even if overtreatment is a major concern in vulnerable populations exposing them to the dangerous consequences of hypoglycemia, the importance of glycemic control should not be underestimated in these populations. First, glucose control should not be allowed to deteriorate with the risk of acute metabolic complications. ${ }^{24}$ Secondly, improving glucose control could remain beneficial even in the very old (patients $>75$ years) provided that diabetes was recently diagnosed ( $<5$ years), as shown in the ZODIAC-20 (Zwolle Outpatient Diabetes project Integrating Available Care) prospective cohort study ${ }^{25}$ In the group with a diabetes duration of $<5$ years, an increase of $1 \%$ in mean $\mathrm{HbA}_{1 \mathrm{c}}$ was associated with an increase in CV mortality risk of $72 \% .{ }^{25}$ Further, the DAS ${ }^{18}$ showed a U-shaped relationship between $\mathrm{HbA}_{1 \mathrm{c}}$ and mortality, with significantly higher mortality rates at $\mathrm{HbA}_{1 \mathrm{c}} \geq 8 \%$ and below $6 \%$. There was a clear, graded relationship between $\mathrm{HbA}_{1 \mathrm{c}}$ and complications, and the authors concluded that their findings strongly support maintaining $\mathrm{HbA}_{1 \mathrm{c}}$ levels below $8 \%$ in elderly patients. The French GERODIAB prospective study will further investigate this important open question of the influence of glycemic control on morbidity/mortality in elderly T2DM patients during a 5-year follow-up period. ${ }^{26}$ Third, even in patients with CKD, it was shown in the ADVANCE study that intensive glucose lowering could prevent major kidney events, with findings consistent across age groups and kidney function. ${ }^{27}$

Thus, rather than neglecting glycemic control to avoid potential overtreatment, one may consider using agents that are less likely to cause hypoglycemia. There is mounting evidence from randomized trials and observational data of the magnitude and risk of hypoglycemia. ${ }^{28,29}$ While severe hypoglycemic events can clearly have dramatic consequences, even milder events represent a significant psychological burden to patients, may result in major anxiety and fear of hypoglycemia, and their repetition predicts future severe episodes. ${ }^{28,30}$ In the elderly, symptoms of hypoglycemia may be atypical and difficult to recognize, resulting in delayed treatment. ${ }^{30}$ In addition, elderly diabetic patients have a marked subjective unawareness of hypoglycemia, an increased reaction time and decreased ability to take corrective actions, all of which contribute to the increased probability of severe hypoglycemia. ${ }^{31}$ Hypoglycemia has been linked to $\mathrm{CV}$ morbidity and mortality. ${ }^{32}$ Moreover, in elderly persons, severe episodes are associated with other serious complications, including falls and fractures that may affect their autonomy, ${ }^{33}$ hospitalization, ${ }^{19,34,35}$ and significant mortality. ${ }^{36,37}$

Our OREDIA population combined the most substantial risk factors for hypoglycemia. The patients were not only old, and as such more susceptible to severe events because of marked decreased hypoglycemia awareness as outlined above, ${ }^{31}$ but also they had renal disease which is an additional significant risk factor of hypoglycemia, in part due to impaired renal neoglycogenesis ${ }^{38}$ and to differential clearance and/or metabolism of anti-hyperglycemic agents. ${ }^{39,40}$ Other additional factors could be polypharmacy (they received a mean of almost six co-medications besides diabetes drugs) $)^{3,25}$ including the use of beta-blockers and angiotensin-converting enzyme inhibitors. ${ }^{41}$ Interestingly, $33.6 \%$ of patients in the recent French GERODIAB survey had experienced one or several hypoglycemia events during the previous 6 months, and $3.3 \%$ had experienced a severe event. ${ }^{26}$ Overall, our geriatric cohort had demographic and disease character- 
istics comparable to the 987 patients aged $\geq 70$ years of GERODIAB, and was well representative of this age group in France. ${ }^{26}$

Comparison with data from the literature on the management of such patients shows similar use of anti-diabetic agents, with consistent high use of SU and glinides. SU and glinides were used by $26 \%$ and $19 \%$ of the OREDIA elderly patients overall, and by $19 \%$ and $21 \%$, respectively, of those with severe RI. Oral IS were still used by $28.3 \%$ of the patients with strict glucose control $\left(\mathrm{HbA}_{1 \mathrm{c}}<7.5 \%\right.$; mean $\mathrm{HbA}_{1 \mathrm{c}} 6.7 \%$ ). Data were captured by therapeutic classes only which did not allow us to differentiate among the various SU. In GERODIAB, SU were prescribed in $28.6 \%$ and glinides in $14.6 \%$ of the patients. In the RIACE (Renal Insufficiency and Cardiovascular Events) Italian study, the use of SU was $34.2 \%$ and $18.1 \%$, respectively, in patients with moderate and severe RI overall and inappropriate prescription of SU further increased with age. ${ }^{42}$ In the US DAS, SU were prescribed to $51 \%$ of the population aged 71 years. ${ }^{8}$ Severe SU-induced hypoglycemia remains life-threatening and under-reported in the geriatric population: Holstein et $\mathrm{al}^{43}$ showed that the main risk factors were indeed age, RI, and polypharmacy. Along with age and renal disease, the SU use was also one of the key variables associated with hospitalization for hypoglycemia in a large retrospective study using claims data from the US. ${ }^{34}$ In the Diaregis ${ }^{44}$ registry in Germany, SU use in elderly patients $\geq 70$ years was again a significant risk of hypoglycemia in multivariate analysis. While glinides can be used in patients with RI, and thus have acquired a definite place especially among DBs as shown in the present study, it is however unclear that they provide a distinct advantage over SU in terms of incidence of hypoglycemia. ${ }^{45}$

As T2DM diabetes progresses, most patients will require insulin replacement therapy, and it is therefore not surprising that insulin was widely used in these patients with longstanding T2DM and CKD. Most often it was combined with OAD although the benefit of such combinations is still under debate with the exception of metformin. However, combining the newer agents, such as DPP-4 inhibitors, with insulin could provide the appealing benefit of improving glucose control without increasing the risk of hypoglycemia, as shown in several recent trials. ${ }^{46}$ Indeed, DPP-4 inhibitors have consistently been associated with a low incidence of hypoglycemia, even in high-risk populations such as the elderly, ${ }^{47}$ patients with $\mathrm{RI}^{48,49}$ or in association with insulin. ${ }^{46}$ However in OREDIA, while they were widely used by GPs, their potential benefit in the most vulnerable patients does not seem to be well recognized as yet, since their use tended to decrease with decreasing RF and increasing insulin use.

The case of metformin is particular. Major discrepancies between current labels and evidence from the literature ${ }^{50}$ suggesting that patients with RI still benefit from using metformin have led to changes in recent guidelines ${ }^{3,15}$ allowing its use in patients with moderate RI. Further, a recent critical examination of lactic acidosis under metformin concluded that metformin was rarely the sole cause of this complication and that the prognosis could even be better in metformintreated patients. ${ }^{50}$ In OREDIA, $30 \%$ of elderly patients with severe RI were receiving metformin, and while the dose was stopped or adjusted at the end of the visit in all cases by the DBs, this was not the case for the GPs.

\section{Strengths and limitations}

This analysis reports data on a relatively large sample of a much neglected population with currently sparse information. It provides a unique description of how an elderly population with T2DM and renal disease is routinely cared for in real life in France. However, one of the main limitations of the study, due to its cross-sectional nature, is the absence of follow-up to show the consequences of potential overtreatment, eg, data about hypoglycemia rates, or about hospitalizations or falls. This is true for most of the recent studies raising the issue of overtreatment. ${ }^{12,16-18}$ Second, the data collected is purely observational and subject to declaration bias; however, data in a real-life setting may have broader applicability than that from clinical trials with restrictive inclusion/exclusion criteria. Another limitation of the present investigation is that the results are based on a sizeable, yet limited, number of patients from a sub-analysis. Furthermore, since the patients were mostly seen in an office practice where geriatric assessment is not routinely done, information that would have allowed characterizing the population with respect to dependency or frailty is lacking.

\section{Conclusion}

Taken together, the present sub-analysis of the OREDIA study provides valuable and novel information about the real-life experience of routinely managing a fragile population of elderly diabetic patients with renal disease in France. It suggests that physicians are not sufficiently adjusting anti-diabetic therapies according to RI and that a substantial proportion of elderly diabetic patients are potentially overtreated. To improve care of elderly diabetic people, future work is needed to increase awareness about this issue of potential diabetic overtreatment in everyday practice. Physicians should re-assess the glycemic 
treatment for a given patient at any routine appointment. The dilemma is to keep the proper balance of a good metabolic control, still important in these patients, while avoiding exposing them to the severe consequences of hypoglycemia.

\section{Acknowledgments}

The authors thank all the patients and investigators at participating sites, Stéphane Quéré and Sylvie di Nicola for statistical support, and Rémy Soulhol for coordinating the study. This work was funded by Novartis Pharmaceuticals Corporation.

\section{Author contributions}

AP participated in study design, contributed to the initial data interpretation and overall clinical interpretation, and was involved in writing and reviewing the manuscript. BF was a key contributor in overall data interpretation and in writing the manuscript. JFB participated in study design, contributed to the initial data interpretation and overall clinical interpretation, and was involved in reviewing the manuscript. SD conceived the study, participated in initial data interpretation and overall clinical interpretation and in writing of the manuscript. All authors were involved in manuscript revisions, approved the final manuscript, and are responsible for intellectual content.

\section{Disclosure}

AP has received fees for consultancy, advisory boards, speaking, travel or accommodation from Abbott, Astra-Zeneca, Boehringer Ingelheim, Bristol-Myers Squibb, Janssen-Cilag, Lilly, Merck Serono, Medtronic, Merck Sharp and DohmeChibret, Novartis, Novo-Nordisk, Pierre Fabre Médicament, Sanofi-Aventis, and Takeda. JFB has received fees for consultancy, advisory boards, speaking, travel or accommodation from Astra-Zeneca, Boehringer Ingelheim, Bristol-Myers Squibb, Janssen, Lilly, Merck Sharp and Dohme, Novartis, Novo-Nordisk, Sanofi-Aventis, and Takeda. BF and SD are employees of Novartis Pharmaceuticals, the sponsor of the present study.

\section{References}

1. Ricci P, Blotière PO, Weill A, Simon D, Tuppin P, Ricordeau P. Diabète traité en France: quelles évolutions entre 2000 et 2009? [Treated diabetes in France: what changes between 2000 and 2009?]. Bull Epidemiol Hebd. 2010; 42:425-431. French.

2. Guariguata L, Whiting DR, Hambleton I, Beagley J, Linnenkamp U, Shaw JE. Global estimates of diabetes prevalence for 2013 and projections for 2035. Diabetes Res Clin Pract. 2014;103(2):137-149.

3. Kirkman MS, Briscoe VJ, Clark N, et al. Diabetes in older adults. Diabetes Care. 2012;35(12):2650-2664.
4. Moreno G, Mangione CM, Kimbro L, Vaisberg E. Guidelines abstracted from the American Geriatrics Society Guidelines for improving the care of older adults with diabetes mellitus: 2013 update. J Am Geriatr Soc. 2013;61(11):2020-2026.

5. Sinclair A, Morley JE, Rodriguez-Manas L, et al. Diabetes mellitus in older people: position statement on behalf of the International Association of Gerontology and Geriatrics (IAGG), the European Diabetes Working Party for Older People (EDWPOP), and the International Task Force of Experts in Diabetes. J Am Med Dir Assoc. 2012;13(6):497-502.

6. Assogba GF, Couchoud C, Roudier C, et al. Prevalence, screening and treatment of chronic kidney disease in people with type 2 diabetes in France: the ENTRED surveys (2001 and 2007). Diabetes Metab. 2012;38(6):558-566.

7. Pornet C, Bourdel-Marchasson I, Lecomte P, et al. Trends in the quality of care for elderly people with type 2 diabetes: the need for improvements in safety and quality (the 2001 and 2007 ENTRED Surveys). Diabetes Metab. 2011;37(2):152-161.

8. Huang ES, Laiteerapong N, Liu JY, John PM, Moffet HH, Karter AJ. Rates of complications and mortality in older patients with diabetes mellitus: the Diabetes and Aging Study. JAMA Intern Med. 2014;174(2): 251-258.

9. Kalyani RR, Saudek CD, Brancati FL, Selvin E. Association of diabetes, comorbidities, and $\mathrm{A}_{1 \mathrm{c}}$ with functional disability in older adults: results from the National Health and Nutrition Examination Survey (NHANES), 1999-2006. Diabetes Care. 2010;33(5):1055-1060.

10. Sue KM, Briscoe VJ, Clark N, et al. Diabetes in older adults: a consensus report. J Am Geriatr Soc. 2012;60(12):2342-2356.

11. Fagot-Campagna A, Bourdel-Marchasson I, Simon D. Burden of diabetes in an aging population: prevalence, incidence, mortality, characteristics and quality of care. Diabetes Metab. 2005;31(Spec No 2): 5S35-5S52.

12. Pogach L, Aron D. The other side of quality improvement in diabetes for seniors: a proposal for an overtreatment glycemic measure. Arch Intern Med. 2012;172(19):1510-1512.

13. Penfornis A, Blickle JF, Fiquet B, Quere S, Dejager S. How are patients with type 2 diabetes and renal disease monitored and managed? Insights from the observational OREDIA study. Vasc Health Risk Manag. 2014;10:341-352.

14. Sinclair AJ, Paolisso G, Castro M, Bourdel-Marchasson I, Gadsby R, Rodriguez ML. European Diabetes Working Party for Older People 2011 clinical guidelines for type 2 diabetes mellitus. Executive summary. Diabetes Metab. 2011;37 Suppl 3:S27-S38.

15. Bonnet F, Gauthier E, Gin H, et al. Expert consensus on management of diabetic patients with impairment of renal function. Diabetes Metab. 2011;37(Suppl 2):S1-S25.

16. Tseng CL, Soroka O, Maney M, Aron DC, Pogach LM. Assessing potential glycemic overtreatment in persons at hypoglycemic risk. JAMA Intern Med. 2014;174(2):259-268.

17. Yeh HC, Huang ES, Levin P, Liu SH, Brancati FL. Medication use in older US adults with diabetes mellitus and the potential ramifications of raising the glycemic target. J Am Geriatr Soc. 2011;59(12): 2381-2383.

18. Huang ES, Liu JY, Moffet HH, John PM, Karter AJ. Glycemic control, complications, and death in older diabetic patients: the Diabetes and Aging Study. Diabetes Care. 2011;34(6):1329-1336.

19. Budnitz DS, Lovegrove MC, Shehab N, Richards CL. Emergency hospitalizations for adverse drug events in older Americans. $N$ Engl $J$ Med. 2011;365(21):2002-2012.

20. Lipska KJ, Ross JS, Wang Y, et al. National Trends in US Hospital Admissions for hyperglycemia and hypoglycemia among medicare beneficiaries, 1999 to 2011. JAMA Intern Med. 2014;174(7): 1116-1124.

21. Bouillet B, Vaillant G, Petit JM, et al. Are elderly patients with diabetes being overtreated in French long-term-care homes? Diabetes Metab. 2010;36(4):272-277. 
22. de Souto BP, Sanz C, Vellas B, Lapeyre-Mestre M, Rolland Y. Drug treatment for diabetes in nursing home residents. Diabetes Med. 2014;31(5):570-576.

23. Andrews MA, O'Malley PG. Diabetes overtreatment in elderly individuals: risky business in need of better management. JAMA. 2014;311(22):2326-2327.

24. Dominguez LJ, Paolisso G, Barbagallo M. Glucose control in the older patient: from intensive, to effective and safe. Aging Clin Exp Res. 2010;22(4):274-280.

25. van Hateren KJ, Landman GW, Kleefstra N, et al. Glycaemic control and the risk of mortality in elderly type 2 diabetic patients (ZODIAC-20). Int J Clin Pract. 2011;65(4):415-419.

26. Doucet J, Le Floch JP, Bauduceau B, Verny C. GERODIAB: glycaemic control and 5-year morbidity/mortality of type 2 diabetic patients aged 70 years and older: 1 . Description of the population at inclusion. Diabetes Metab. 2012;38(6):523-530.

27. Perkovic V, Heerspink HL, Chalmers J, et al. Intensive glucose control improves kidney outcomes in patients with type 2 diabetes. Kidney Int. 2013;83(3):517-523.

28. Cryer PE. The barrier of hypoglycemia in diabetes. Diabetes. 2008; 57(12):3169-3176.

29. Holstein A, Patzer OM, Machalke K, Holstein JD, Stumvoll M, Kovacs P. Substantial increase in incidence of severe hypoglycemia between 1997-2000 and 2007-2010: a German longitudinal populationbased study. Diabetes Care. 2012;35(5):972-975.

30. Barnett AH, Brice R, Hanif W, James J, Langerman H. Increasing awareness of hypoglycaemia in patients with type 2 diabetes treated with oral agents. Curr Med Res Opin. 2013;29(11):1503-1513.

31. Bremer JP, Jauch-Chara K, Hallschmid M, Schmid S, Schultes B. Hypoglycemia unawareness in older compared with middle-aged patients with type 2 diabetes. Diabetes Care. 2009;32(8):1513-1517.

32. Sanon VP, Sanon S, Kanakia R, et al. Hypoglycemia from a Cardiologist's perspective. Clin Cardiol. 2014;37(8):499-504.

33. Schwartz AV, Vittinghoff E, Sellmeyer DE, et al. Diabetes-related complications, glycemic control, and falls in older adults. Diabetes Care. 2008;31(3):391-396.

34. Fu H, Xie W, Curtis B, Schuster D. Identifying factors associated with hypoglycemia-related hospitalizations among elderly patients with T2DM in the US: a novel approach using influential variable analysis. Curr Med Res Opin. 2014;30(9):1787-1793.

35. Ginde AA, Pallin DJ, Camargo CA Jr. Hospitalization and discharge education of emergency department patients with hypoglycemia. Diabetes Educ. 2008;34(4):683-691.

36. Garg R, Hurwitz S, Turchin A, Trivedi A. Hypoglycemia, with or without insulin therapy, is associated with increased mortality among hospitalized patients. Diabetes Care. 2013;36(5):1107-1110.

37. Majumdar SR, Hemmelgarn BR, Lin M, McBrien K, Manns BJ, Tonelli M. Hypoglycemia associated with hospitalization and adverse events in older people: population-based cohort study. Diabetes Care. 2013;36(11):3585-3590.
38. Gerich JE, Meyer C, Woerle HJ, Stumvoll M. Renal gluconeogenesis: its importance in human glucose homeostasis. Diabetes Care. 2001;24(2): 382-391.

39. Davis TM, Brown SG, Jacobs IG, Bulsara M, Bruce DG, Davis WA. Determinants of severe hypoglycemia complicating type 2 diabetes: the Fremantle diabetes study. J Clin Endocrinol Metab. 2010;95(5): 2240-2247.

40. Moen MF, Zhan M, Hsu VD, et al. Frequency of hypoglycemia and its significance in chronic kidney disease. Clin J Am Soc Nephrol. 2009;4(6):1121-1127.

41. Chelliah A, Burge MR. Hypoglycaemia in elderly patients with diabetes mellitus: causes and strategies for prevention. Drugs Aging. 2004;21(8): 511-530.

42. Solini A, Penno G, Bonora E, et al. Age, renal dysfunction, cardiovascular disease, and antihyperglycemic treatment in type 2 diabetes mellitus: findings from the Renal Insufficiency and Cardiovascular Events Italian Multicenter Study. J Am Geriatr Soc. 2013;61(8):1253-1261.

43. Holstein A, Hammer C, Hahn M, Kulamadayil NS, Kovacs P. Severe sulfonylurea-induced hypoglycemia: a problem of uncritical prescription and deficiencies of diabetes care in geriatric patients. Expert Opin Drug Saf. 2010;9(5):675-681.

44. Bramlage P, Gitt AK, Binz C, Krekler M, Deeg E, Tschope D. Oral antidiabetic treatment in type- 2 diabetes in the elderly: balancing the need for glucose control and the risk of hypoglycemia. Cardiovasc Diabetol. 2012;11:122.

45. Phung OJ, Scholle JM, Talwar M, Coleman CI. Effect of noninsulin antidiabetic drugs added to metformin therapy on glycemic control, weight gain, and hypoglycemia in type 2 diabetes. JAMA. 2010;303(14):1410-1418.

46. Charbonnel B, Schweizer A, Dejager S. Combination therapy with DPP-4 inhibitors and insulin in patients with type 2 diabetes mellitus: what is the evidence? Hosp Pract (1995). 2013;41(2):93-107.

47. Bourdel-Marchasson I, Schweizer A, Dejager S. Incretin therapies in the management of elderly patients with type 2 diabetes mellitus. Hosp Pract (1995). 2011;39(1):7-21.

48. Dejager S, Schweizer A. Incretin therapies in the management of patients with type 2 diabetes mellitus and renal impairment. Hosp Pract (1995). 2012;40(2):7-21.

49. Schweizer A, Dejager S. Experience with vildagliptin in patients $>/=75$ years with type 2 diabetes and moderate or severe renal impairment. Diabetes Ther. 2013;4(2):257-267.

50. Lalau JD, Arnouts P, Sharif A, De Broe ME. Metformin and other antidiabetic agents in renal failure patients. Kidney Int. 2015;87(2) $308-322$.

Diabetes, Metabolic Syndrome and Obesity: Targets and Therapy

Dovepress

\section{Publish your work in this journal}

Diabetes, Metabolic Syndrome and Obesity: Targets and Therapy is an international, peer-reviewed open-access journal committed to the rapid publication of the latest laboratory and clinical findings in the fields of diabetes, metabolic syndrome and obesity research Original research, review, case reports, hypothesis formation, expert opinion and commentaries are all considered for publication. The manuscript management system is completely online and includes a very quick and fair peer-review system, which is all easy to use. Visit http://www.dovepress.com/testimonials.php to read real quotes from published authors. 